UH

iti

Universität Hamburg
Faculty Economics and Social Sciences Chair for Economic Policy

WOLFGANG MAENNIG/ MICHAEL STOBERNACK

\title{
DO MEN SLOW DOWN FASTER THAN WOMEN?
}

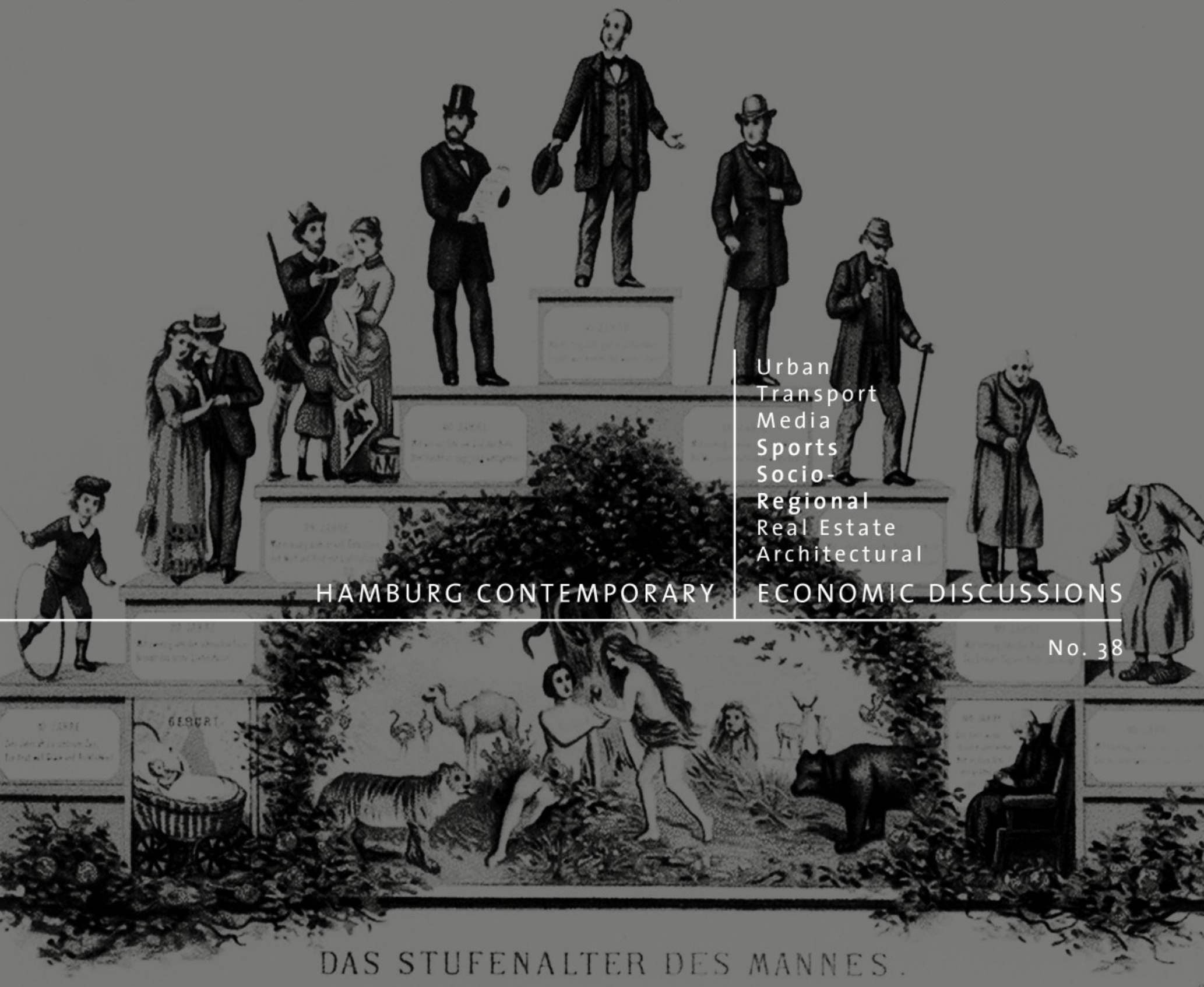


Hamburg Contemporary Economic Discussions

University of Hamburg

Faculty Economics and Social Science

Chair for Economic Policy

Von-Melle-Park 5

D-20146 Hamburg | Germany

Tel $+494042838-4622$

$\mathrm{Fax}+494042838-6251$

http://www.uni-hamburg.de/economicpolicy/

Editor: Wolfgang Maennig

Wolfgang Maennig

University of Hamburg

Faculty Economics and Social Science

Chair for Economic Policy

Von-Melle-Park 5

D-20146 Hamburg | Germany

$\mathrm{Tel}+494042838-4622$

Fax $+494042838-6251$

maennig@econ.uni-hamburg.de

Michael Stobernack

Brandenburg University of Applied Sciences

Fachhochschule Brandenburg

Department of Business Administration

Magdeburger Str. 50

D-14770 Brandenburg a.d. Havel

Tel +493381355239

Fax +493381355299

stobernack@fh-brandenburg.de

ISSN 1865 - 2441 (Print)

ISSN 1865 - 7133 (Online)

ISBN $978-3-940369-88$ - 8 (Print)

ISBN 978-3-940369-89-5 (Online) 


\title{
Do Men Slow Down Faster than Women?
}

\begin{abstract}
This paper is the first test of differences between age-related reductions in the performance of men and women. The assumption that men age faster is obvious, because men's life expectancy is generally lower. In addition to other studies on age-related reduction in human performance, this paper examines the data taken from competitions on rowing machines, which have been standardized worldwide and which are hardly affected by weather or temperature. A third innovation is that this study looks for any potential ageing processes specific to gender and physique. Fourth, fractional polynomials have been added to the testing methodology. Contrary to intuition, we find evidence that women are affected by faster age-related reductions in performance.
\end{abstract}

Keywords: Labor productivity, ageing economics, economics of gender

JEL classification: J16, J24

Version: October 2009

\section{Introduction}

In most regions of the world, populations will age significantly in future decades, and considerably decline in number. ${ }^{1}$ These envisaged demographic developments might have a significant effect on the pension, health and nursing care insurance systems, and have been extensively underpinned by data and recognized by the general population. The projected effects usually heavily depend on the assumption of future life expectancies, future pension ages, etc. They also depend on assumptions on the productivity effect of an ageing work force a parameter which is addressed by this paper.

Labour productivity could be affected negatively by the rising average age, because physical fitness and the ability for problem solving, learning and mental speed as well as verbal abilities may decline with age, and because people's appetite for risk-taking also generally reduces with age. However, senior employees may have a wider professional network and more tacit knowledge; may tend to uphold norms of social behaviour more than their younger counterparts; and may

1 Cf. for a global comparison and literature sources, United Nations Organization (2003) and Mc Morrow and Roeger (2004). 
have better professional experience, including better procedural knowledge, especially for problems arising with relatively low frequency. They may also have a better insight into human nature. There are four major groups of methods of empirical studies analyzing individual age productivity profiles. ${ }^{2}$ The first group of studies based on supervisors' ratings typically does not find any clear systematic age-productivity relationship, but may be biased because managers may wish to reward older employees for their loyalty and past achievements (SALTHOUSE \& MAURER, 1996). In a second group of studies that use employer-employee matched data sets, individuals typically have the highest productivity levels in their $30 \mathrm{~s}$ and $40 \mathrm{~s} .{ }^{3}$ The main challenge in this approach is to isolate the effect of employees' age from other influences on the company's value-added, which leads to strong identifying assumptions (SKIRBEKK, 2004).

A third group of studies uses age-earnings profiles. British male workers in the first half of the 19th century until the 1930s, when there were few regulations in the labour market, reached their peak earnings in their 30s, with wages decreasing substantially after 40 years of age (BOOT, 1995; JOHNSON, 2003). In modern labour markets, wages may reflect current productivity to a limited extent only. KOTLIKOFF \& WISE (1989) find that salary earnings of US sales workers who are paid according to the number and amounts of insurance contracts they negotiate double from the early 20 s to early 40 s, remain relatively constant up to the age of 55 , and then decline by up to 25 percent from age 65 onwards. The starting salaries of office employees, which may be more useful in measuring work productivity due to a potential seniority effect, also rise between the early 20s and mid-40s, only to fall relatively sharply right after. At 60 , office workers achieve only 60 percent of the maximum starting salary. OECD (1998) observes that gross wages for

2 There are also studies which model the age productivity relationship on a macroeconomic level. For example, NISHIMURA et al. (2002) find that the relation between the share of educated workers older than 40 years and technological progress in Japan was positive in the 1980s, but turned negative in the 1990s. This may indicate a higher rate of technological change in the latter decade which shifted the productivity peak towards a younger age.

3 Cf. CRÉPON et al. (2003), ILMAKUNNAS et al. (2004), HALTIWANGER et al. (1999), H/EGELAND \& KLETTE (1999). 
the 25-29 age group in 17 out of 19 member countries are on average 72 percent of what the 45-54 age group earns, while the 55-64 age group earns 91 percent of what the 44-54 age group does. ${ }^{4}$ In addition to that and in general in modern labour markets, wages are lower than productivity levels at younger ages and higher than productivity levels at higher ages. ${ }^{5}$

Empirical studies using the fourth method, piece-rate studies, suggest that productivity follows an inverted U-shaped profile where significant decreases are found after the age of $50 .^{6}$

The described diversity of empirical findings may also be related to the steadily changing importance of the different factors in determining individual productivity. ${ }^{7}$ For example, structural changes in the labour market and accelerating technological progress can increase the importance of learning abilities. Long work experience ${ }^{8}$, physical abilities, and possibly education may have lost importance in recent times. The importance of the different factors in determining individual productivity also varies according to profession (WARR, 1994).

As a solution, studies have been carried out to test separately for the different factors of individual productivity. Studies on cognitive abilities, such as reasoning,

4 In contrast, LAZEAR \& MOORE (1984) find that salary workers have increasing wages throughout their career, while the self-employed have little wage variation over the life cycle.

5 Cf. SKIRBEKK (2004). Several theories have been brought forward to explain the difference between age-earnings profiles and age-productivity profiles. Such delayed payment contracts may be used when workers' performance is difficult to observe and measure (HARRIS \& HOLMSTROM, 1982; HUTCHENS, 1989). Employers may use upwardly sloping wage profiles to raise shirking costs of employees to lower the companies' need to train new workers and to decrease the risk of company secrets being leaked to competing companies because of low staff turnover.

6 This is true also for researchers and their number of publications and the standard of the journals in the fields of biochemistry, economics, geology, physics, and physiology.

7 For a literature survey on the determinants of (labour) productivity, see cf. SKIRBEKK (2004).

8 The role of job experience may be overestimated generally: job duration improves job performance for only something in between 4 years for manufacturing employees (ILMAKUNNAS et al., 2004) and 10 years in jobs where strategic and analytic competence is important (ERICSSON \& LEHMANN, 1996). 
speed, and episodic memory, generally show a significant decline by the age of 50 (VERHAEGEN \& SALTHOUSE, 1997). Age-induced changes of these abilities are similar for both men and women, and across countries (MAITLAND et al., 2000; PARK et al., 1999).

Athletic performance - mostly related to physical performance - seems to start decreasing earlier, but may decrease at a lower rate at later ages. On the basis of a study of 27 athletic disciplines and the "Master Age Records" for men in the field in 1990 that lists world records for each age, FAIR (1994) finds that top men in their age groups only require 50 percent more time from the age of 74 than the absolute world record holder - twice as much only from the age 91 . Between the ages of 45 and 60 , where starting salaries for office workers shrink by up to 40 percent according to KOTLIKOFF \& WISE (1989), performance drops only by approximately 15 percent. ${ }^{9}$ Analogous findings for women have been made in an analogous study on swimming (FAIR, 2007) and baseball although aging effects are larger for baseball (FAIR, 2008).

This paper uses the top $\mathrm{N}=1$ performances by age class from competitions on rowing machines ("Concept2"). Using data of the 'best' athletes might well be helpful to narrow down the age-productivity profile of the 'average' performer, as the rate of decline appears to be the same among top performers as among others (OSTER \& HAMERMESH, 1998; DEARY et al., 2000). Unlike in track-and-field sports and swimming used by FAIR $(1994,2007)$, results on rowing machines, which are standardized worldwide, are barely affected by weather or temperature. It should also be pointed out that rowing, in contrast to track-and-field sports and swimming studied so far, is virtually unaffected by doping..$^{10}$ This paper adds to the evidence on physical age-performance profiles. Rowing 2000 meters successfully might be primarily a physically related issue. Nevertheless, it also requires substantial abilities for self-conquest, concentration, and pacing oneself,

9 For references to comparable studies in connection with (sport) medicine, cf. FAIR (1994).

${ }_{10}$ Nine doping cases were identified during the 2008 Olympic Games, four of which concerned track-and-field sports, but none in rowing (cf. WADA, 2009, p.30). 
and a high level of self-command - abilities which lie in the realm of mental or psychological factors (RUSHALL, 2000).

Second, the paper adds to the literature by explicitly examining differences in age-related performance decline between men and women. More rapid ageing in men is an obvious assumption, because men's life expectancy is lower in all the countries known to the authors. If such differences exist, they could lead to an increase in society's work productivity due to the future growth of the share of working women, which has been underestimated by projections thus far. Third, this paper expands on the findings thus far, because the weight classes in rowing are analyzed separately for lightweights and the open class. By examining significant differences between the four groups of characteristics (men/women; lightweight/open class), it is possible to discover any different ageing processes that are specific to gender or physique. Fourth, further potential functional forms are tested: In addition to a continuously square course of the function, using fractional polynomials an examination is made to find out whether there are hitherto unknown powers and combinations of the exogenous variable age, which may give a better explanation for the decrease in performance.

\section{Data and empirical strategy}

The top $\mathrm{N}=1$ performances by age class, measured by the best times between 2002 and 2005 for the four different characteristics of open class men and women as well as lightweight men ( $<75 \mathrm{~kg}$ and women $<61.5 \mathrm{~kg})^{11}$ were obtained from the website of the international rowing federation ${ }^{12}$ and limited to male and

11 These weight classes of Concept2 competitions differ from the weight classes of the international rowing federation FISA for rowing competitions in boats $(72.5 / 59 \mathrm{~kg})$, because many athletes pursue indoor rowing mainly outside the summer rowing competition season and because they want to avoid that lightweight athletes that are near the upper weight limit slip into the open class after gaining weight during a period of no competitions.

${ }^{12}\left\langle\right.$ http://www.worldrowing.com/events/default.sps $>$ from November, $8^{\text {th }} 2005$ 
female athletes who are between 35 and 70 years old. ${ }^{13}$ The "classical" race distance of 2,000 meters has been chosen in order to obtain a relatively large random sample. In this case the competitive stress is typically between 347.1 (40year-old man - open class) and 621.2 seconds (69-year-old woman - lightweight, table 1). Figure 1 shows, by way of example, the respective logarithms of the required best times for different age groups of the men's open class.

Fig. 1 Men (Open class): Observed and curve-fitted data according to models (1), (2) and (3)

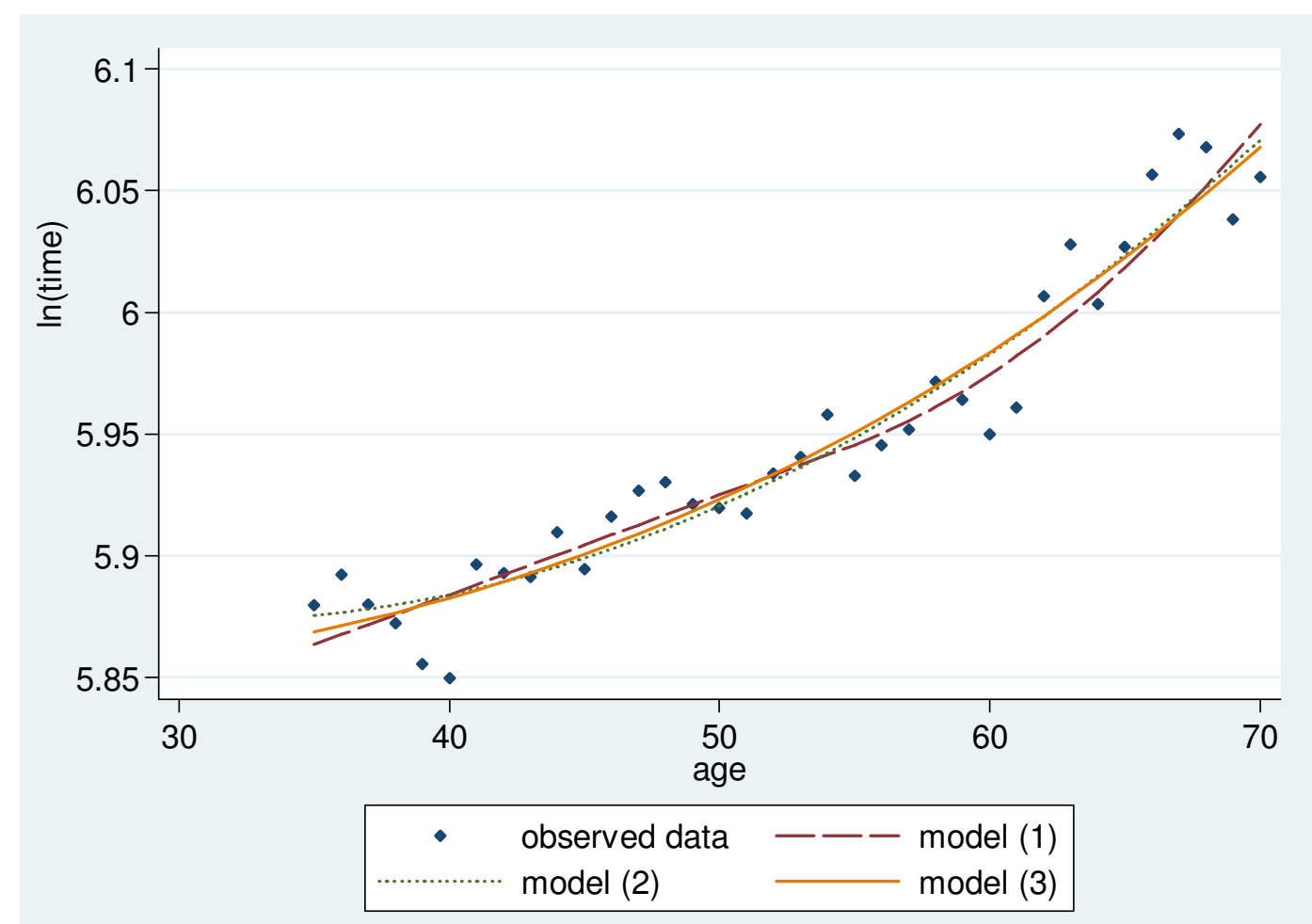

${ }^{13}$ In an earlier version of the paper, we tested for older persons as well. An anonymous referee pointed out that this might not be helpful to draw conclusions on age-productivity profiles for the labour force. The results including older persons are available from the authors on request. 
We regress the natural logarithm of the time rowed (in seconds) at first in a way analogous to Fair $(1994,2007)$, where a linear course of the function is assumed up to a specific age $\mathrm{k}^{*}$ (hereinafter "performance drop"). For ages above that, a square performance drop is assumed. $\mathrm{k}^{*}$ must be estimated from the data together with $\beta_{i \cdot}{ }^{14}$

$\ln ($ time $)=\beta_{0}+\beta_{1}$ age $+\beta_{2} \mathrm{dk} \cdot\left(\mathrm{k}^{*^{2}}-2 \mathrm{k}^{*}\right.$ age + age $\left.^{2}\right)+\varepsilon$

with

$d k=0 \quad \forall a g e \leq k^{*}$ and

$d k=1 \quad \forall a g e>k^{*}$

Tab. 1 Descriptive Statistics

\begin{tabular}{ccccc}
\hline & $\begin{array}{c}\text { Men Open } \\
\text { Class }\end{array}$ & $\begin{array}{c}\text { Men } \\
\text { Lightweight }\end{array}$ & $\begin{array}{c}\text { Women Open } \\
\text { Class }\end{array}$ & $\begin{array}{c}\text { Women } \\
\text { Lightweight }\end{array}$ \\
\hline race time, mean (in sec) & 383,5 & 402,9 & 459,7 & 474,7 \\
Standard deviation & 24,3 & 19,2 & 37,5 & 41,1 \\
Minimum race time & 347,1 & 378,2 & 406,8 & 424,1 \\
Maximum race time & 434,1 & 447,3 & 568,6 & 621,2 \\
Age from ... To ... & $35-70$ & $35-70$ & $35-70$ & $35-70$ \\
$\mathrm{~N}$ & 36 & 36 & 36 & 36 \\
\hline
\end{tabular}

Since a visual inspection of the data makes even continuously square courses of the function appear plausible for the entire age range instead of a linear function for the first part of the age range and a quadratic function for the second part after a performance drop (see Figure 1 for men in the open class), a corresponding second model has been estimated:

$\ln ($ time $)=\beta_{0}+\beta_{1} a g e+\beta_{3} a g e^{2}+\varepsilon$

${ }^{14}$ For details see the appendix of FAIR (2007). 
Finally, we estimate, using the method of fractional polynomials (ROYSTON \& ALTMAN, 1994), whether there are any other powers of the exogenous variable age whose application may result in better class properties. The advantage of using fractional polynomials is that, unlike (1) and (2), only a specific class of functions is given, rather than a special form within such class. On the basis of the likelihood-ratio test, each function form is filtered out that provides the best fit. Thus, the form of the function itself is a subject of the estimate. Fractional polynomials originated and are most commonly used in medical research (ROYSTON \& SAUERBREI, 2008).

$\ln ($ time $)=\beta_{0}+\sum_{j=1}^{J} F_{j}($ age $) \beta_{j}+\varepsilon$

with $F_{j}$ being a special type of a power function.

$F_{1}(x)=x^{p_{1}} \quad p_{1} \in\{-2,-1,-.5,0, .5,1,2,3\} \quad$ and

$F j(x)=\left\{\begin{array}{ll}x^{p_{j},} & p_{j} \neq p_{j-1} \\ F_{j-1}(x) \ln (x), & p_{j}=p_{j-1}\end{array} \quad j=2, \ldots, J\right.$ and $p_{j} \in\{-2,-1,-5,0, .5,1,2,3\}$

where $p=0$ means $\ln (x)$

For example, if we chose $\mathrm{J}=1$ with $\mathrm{p}_{1}=3$, we get

$\ln ($ time $)=\beta_{0}+\beta_{4} \cdot a g e^{3}+\varepsilon$

For example, if we chose $\mathrm{J}=2$ with $\mathrm{p}_{1}=0$ and $\mathrm{p}_{2}=-0.5$, we get

$\ln ($ time $)=\beta_{0}+\beta_{5} \cdot \ln (x)+\beta_{6} \cdot \frac{1}{\sqrt{x}}$

There is a variety of power functions - one of them is supposed to be the best fitted model among this type of function according to the largest log likelihood and the smallest deviance (i.e. $-2^{*} \log$ likelihood), respectively. With $\mathrm{J}=1$ there are eight models to be estimated, with $\mathrm{J}=2$ we get 36 different models. For the $\mathrm{J}=1$ models we observe a best model and for the $\mathrm{J}=2$ models we get another best model. Each is compared to the linear model by using the difference in the deviances to check whether it is worth using that specific model instead of the linear model. 


\section{Results}

We start by rejecting the idea that there are not any differences in age-dependent performance trends in the four groups of people studied. The Chow-test in table 2 shows significant differences concerning the age of the performance drop and that the ageing process then progresses at different speeds thereafter, when using estimate model ( 1 ) - in addition to the expected differences in the constant that approximates absolute performance levels. When using model (3), differences are also identified in the rate of the ageing processes in addition to the differences in the constant. It is from this point of view that the four groups of people are to be analyzed separately at first ${ }^{15}$.

Tab. 2 Chow Test for Parameter Equality in All Four Groups (Women and Men, Lightweight and Open Class)

\begin{tabular}{cccc}
\hline Variable & $\begin{array}{c}\text { Model (1) } \\
\text { F-value }\end{array}$ & $\begin{array}{c}\text { Model (2) } \\
\text { F-value }\end{array}$ & $\begin{array}{c}\text { Model (3) } \\
\text { F-value }\end{array}$ \\
\hline Overall without constant & $8,4^{* * *}$ & $5,4^{* * *}$ & $5,0^{* * *}$ \\
Constant & $5,1^{* * *}$ & 0,3 & $341,5^{* * *}$ \\
$\beta_{1}$ & $3,7^{* *}$ & 0,0 & \\
$\beta_{2}$ & $10,1^{* * *}$ & & \\
$\mathrm{k}^{*}$ & $23,9^{* * *}$ & & \\
$\beta_{3}$ & & 0,1 & \\
$\beta_{4}$ & & & $5.0^{* * *}$ \\
\hline
\end{tabular}

Notes: ${ }^{*} /{ }^{* *} /{ }^{* * *}=$ significant at the $10 \% / 5 \% / 1 \%$ level.

In men of the open class, deviance values in table 3 indicate an equality of models (1), (2) and (3). The J-test does not indicate misspecification for all three models,

${ }^{15}$ For model (2), there is a difference in the overall model between the four groups although the hypothesis of equality for every single coefficient can not be rejected. 
whereas with the RESET test the hypothesis of no misspecification has to be rejected for model (2).

For the lightweight class, the adjustment quality of all models is the same since there is no significant difference between the deviance values (table 3). The J-test and RESET test do not indicate misspecification for any of the three models.

All coefficients exhibit in all three models the expected signs and are significant at the five-percent level (table 3). Figure 1 illustrates that the progression of the estimated times rowed of the men's open class is almost identical in models (2) and (3). In the case of 35-41-year-olds and 65-70-year-olds, however, model (3) adjusts for longer competition times, and shorter ones for the 42-64-year-olds. 
Tab. 3 Performance, in $\ln (\mathrm{sec} / \mathbf{2 0 0 0 m})$, men

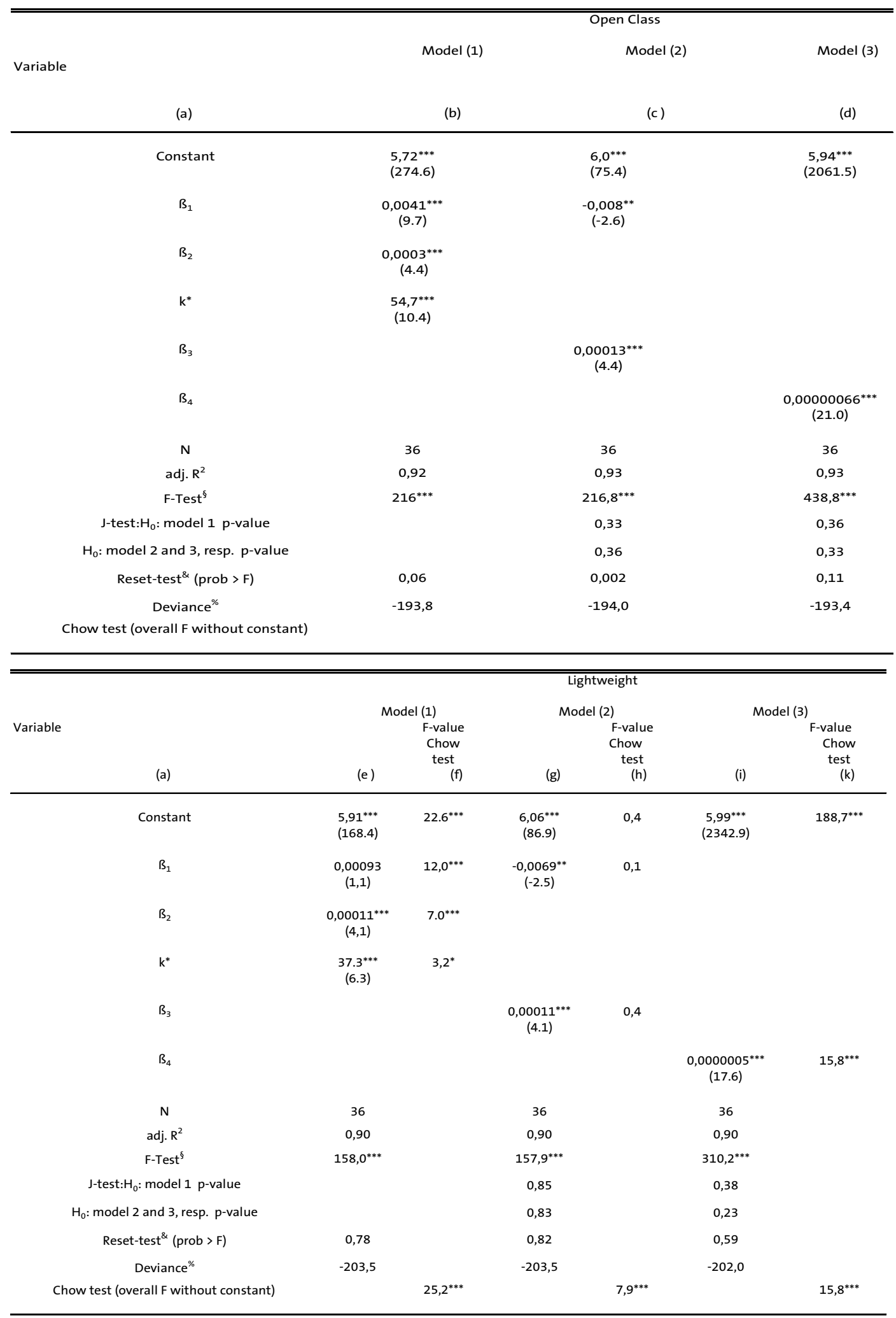

remarks: ${ }^{* * *} /{ }^{* * *}=$ significant at the $10 \% / 5 \% / 1 \%$ level. T-values are in parentheses.

$\S H_{0}$ : all coefficients $=$ zero

\& $\mathrm{H}_{0}$ : model has no omitted variables 
The regression results can be converted to age elasticities of performance. Fortyyear-old men in the open class lose between 3.8 and 4.2 percent of their performance in the decade ahead of them, depending on the estimated model (table 4, line 5, columns 2-4). This decade-specific loss of performance increases with growing age; 60-year-olds lose between 8.7 and 10.8 percent of their performance in the decade ahead of them.

For completeness' sake, it should be noted that a 70-year-old, when compared to a 35-year-old, requires 22 to 24 percent more time for the competition distance across all models (table 4, line 4, columns 2-4). 
Tab. 4 Age Factors and Age Elasticities

\begin{tabular}{|c|c|c|c|c|c|c|c|}
\hline \multicolumn{8}{|c|}{ Men } \\
\hline & \multirow{3}{*}{1} & \multicolumn{3}{|c|}{ Open Class } & \multicolumn{3}{|c|}{ Lightweight } \\
\hline & & 2 & 3 & 4 & 5 & 6 & 7 \\
\hline & & \multicolumn{6}{|c|}{ Age factors (reference 35year old) } \\
\hline Line & Age & Model (1) & Model (2) & Model (3) & Model (1) & Model (2) & Model (3) \\
\hline 1 & 40 & 1,02 & 1,01 & 1,01 & 1,01 & 1,01 & 1,01 \\
\hline 2 & 50 & 1,06 & 1,05 & 1,06 & 1,03 & 1,04 & 1,04 \\
\hline 3 & 60 & 1,12 & 1,11 & 1,12 & 1,08 & 1,09 & 1,09 \\
\hline 4 & 70 & 1,24 & 1,22 & 1,22 & 1,16 & 1,18 & 1,16 \\
\hline & & \multicolumn{6}{|c|}{ 10-year age elasticities } \\
\hline 5 & 40 & 4,2 & 3,8 & 4,1 & 2,7 & 3,0 & 3,1 \\
\hline 6 & 50 & 5,1 & 6,5 & 6,2 & 4,9 & 5,3 & 4,7 \\
\hline 7 & 60 & 10,8 & 9,3 & 8,7 & 7,3 & 7,7 & 6,6 \\
\hline \multicolumn{8}{|c|}{ Women } \\
\hline & & \multicolumn{3}{|c|}{ Open Class } & \multicolumn{3}{|c|}{ Lightweight } \\
\hline & & \multicolumn{6}{|c|}{ Age factors (reference 35year old) } \\
\hline 8 & 40 & 1,03 & 1,01 & 1,02 & 1,03 & 1,01 & 1,02 \\
\hline 9 & 50 & 1,10 & 1,06 & 1,07 & 1,08 & 1,06 & 1,06 \\
\hline 10 & 60 & 1,16 & 1,13 & 1,15 & 1,13 & 1,13 & 1,13 \\
\hline 11 & 70 & 1,24 & 1,25 & 1,28 & 1,33 & 1,24 & 1,24 \\
\hline & & \multicolumn{6}{|c|}{ 10-year age elasticities } \\
\hline 12 & 40 & 6,3 & 4,4 & 5,1 & 5,1 & 4,5 & 4,5 \\
\hline 13 & 50 & 6,3 & 7,4 & 7,6 & 5,1 & 7,0 & 6,8 \\
\hline 14 & 60 & 6,3 & 10,4 & 10,8 & 17,5 & 9,6 & 9,6 \\
\hline
\end{tabular}

Notes: For example, the age factor for age 40 is $\mathrm{Y}_{40} / \mathrm{Y}_{35}$ with $\mathrm{Y}=\ln$ (time) according to the specific model.

For example, the 10-year age elasticity for age 40 in line 5 is $\left(Y_{50} / Y_{40}-1\right)^{*} 100$.

The estimates for lightweight men show a similarly high explanatory power. According to the deviance values, there is no significant difference between the estimates. Here, too, all the coefficients have the expected signs and are significant at the five-percent error level. The age of the performance drop determined endogenously in model (1) sets in for the lightweight class only at age 37, that is, about 18 years earlier than in men of the open class. According to the Chow test, 
however, this difference is only significant at the ten-percent error level (table 3, column (f)). Besides $\beta_{2}, \beta_{1}$ is also significantly smaller - as expected - for the lightweight than for the open class at least at the five-percent level. In other words, the decline following the performance drop is stronger for the open class.

When converted to decade-based performance losses, performance in lightweight's 40 s and 50 s drops by 2.7 to 4.9 percent in a span of ten years - a value similar to men of the open class. The discrepancy in estimates on the relative performance of 70-year-old lightweights is moderate. They require 16 to 18 percent more time than a 35-year old.

For women of both the open and lightweight classes, deviance values show no significant difference between the three models. The coefficients show the expected signs and, apart from $\aleph_{1}$ in model (2), they are significantly different from zero for women of the open performance class (table 5). The constant for lightweight women under model (3)-as expected-is significantly higher than for the open performance class - this is not the case with models (1) and (2).

Accordingly, the age elasticities in all estimate models are conspicuously similar (table 4, rows 12-14). With each decade the performance decline increases by approximately three percentage points, starting with approximately 5 percent for women in their forties and reaching up to 17.5 percent for women in their sixties. 
Tab. 5 Performance, in $\ln (\mathrm{sec} / 2000 \mathrm{~m})$, women

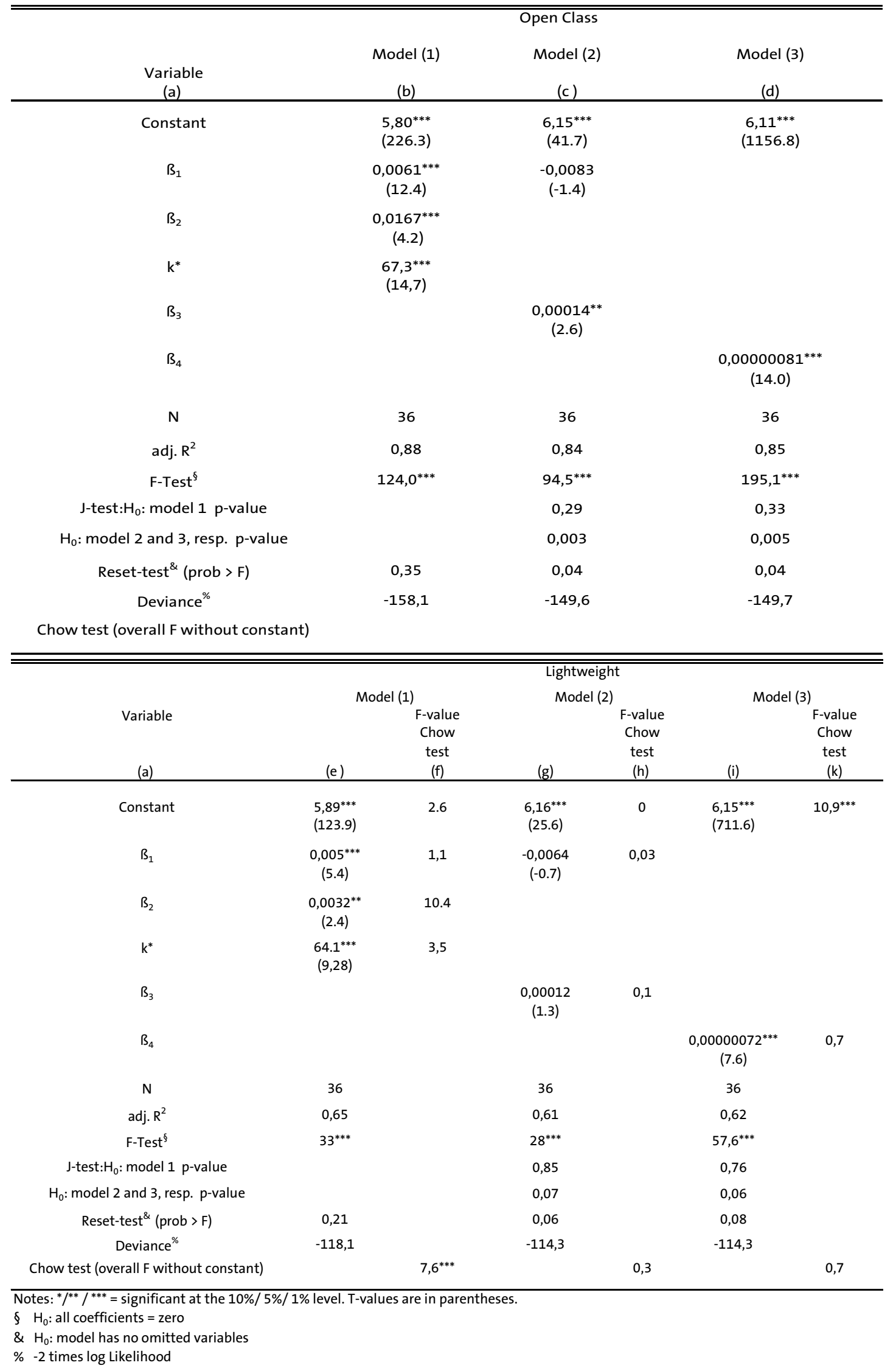


Table 6 presents the test results regarding different age-related differences in performance for men and women that abstract from absolute performance, which is expressed in the constants.

Under model (2), for which the RESET test indicated misspecification in the case of men of the open class, there are no differences in the performance loss between men and women in the open class and the lightweights. According to models (1) and (3), women in both weight classes experience a performance loss that is stronger than for men.

Tab. 6 Chow Test for Parameter Equality between Men and Women (F-value)

\begin{tabular}{|c|c|c|c|c|c|c|}
\hline & \multicolumn{3}{|c|}{ Open Class } & \multicolumn{3}{|c|}{ Lightweight } \\
\hline & Model (1) & Model (2) & Model (3) & Model (1) & Model (2) & Model (3) \\
\hline & $\mathrm{F}$ & $\mathrm{F}$ & $\mathrm{F}$ & $\mathrm{F}$ & $\mathrm{F}$ & \\
\hline Variable & & & & & & \\
\hline $\begin{array}{l}\text { Overall without } \\
\text { constant }\end{array}$ & $18^{* * *}$ & $2,5^{*}$ & $5,0^{* *}$ & $13,1^{* * *}$ & $2,6^{*}$ & $5,2^{* *}$ \\
\hline Constant & $6,7^{* *}$ & 0,9 & $868,6^{* * *}$ & 0,1 & 0,2 & $307,4^{* * *}$ \\
\hline$\beta_{1}$ & $8,7^{* * *}$ & 0 & & $10,5^{* * *}$ & 0 & \\
\hline$B_{2}$ & $17,0^{* * *}$ & & & $5,3^{* *}$ & & \\
\hline $\mathrm{k}^{*}$ & $6,4^{* * *}$ & & & $5,5^{* *}$ & & \\
\hline$B_{3}$ & & 0,1 & & & 0,02 & \\
\hline$\beta_{4}$ & & & $5.0^{* *}$ & & & $5.2^{* *}$ \\
\hline
\end{tabular}

\section{Discussion}

In estimating age-induced performance losses, our models with fractional polynomials did not identify better adjustment properties either for women or for men as opposed to models used beforehand by FAIR $(1994,2007)$. Our model with 
a continuously square age-dependent performance decline was identified to be misspecified according to the RESET test in the case of men of the open class, although not on the basis of the J-test. Leaving aside the (model-dependent) differences beyond FAIR's $(1994,2007)$ performance drop, the findings of our estimates for rowing ergometers confirm that his scale of performance decreases for other sports, with increasing performance losses. For example, 40-year-old men in the open class lose some four percent of their performance in the decade ahead of them. This decade-specific loss of performance increases with growing age; 60year-olds lose (model-depending) between 8.7 and 10.8 percent of their performance in the following decade.

Concentrating on models (1) and (3), which did not show potential misspecification problems, we find evidence for age-related performance reductions for women that are larger than for men in both weight classes - a result that seems to be in intuitive contrast to the fact that men's life expectancy is generally lower.

Our results show a steady decrease in physical performance from the very beginning of our data sample starting at 35 years old. The above mentioned studies, which do not concentrate on only one of the factors of the age related productivity profiles, but measure productivity by wages, piece-rates etc. (thus the result of the combination of different factors), mostly show productivity rises at first up to the early 40s. The later studies then show declines on average by 25 to 40 percent until the 60s. Physical performance, however, drops only by approximately 15 percent before reaching one's 60 s.

In the first instance, our investigations might be relevant only for activities in working life that mostly require physical performance. On the other hand, if the difference in progression of physical performance and work productivity in the thirties and forties is explained by professional experience, insight into human nature, organizational knowledge, etc., then the question as to why the subsequent drop in work productivity is more marked than that in physical performance will have to be answered. Possible explanations can be found in "real" phenomena such as a decreased willingness to take risk. Another possible approach to finding an explanation could be found in the productivity of older people as 
perceived by the labour market, which does not follow "real" circumstances. In this case, it would be worthwhile examining why the ability of older people is systematically underestimated by the labour market.

Finally, if it is argued contrary to the evidence of OSTER \& HAMERMESH (1998) and DEARY et al. (2000) that the estimated results of physical performance decline are based on the data of well-exercised people of different age groups, while normal (or non-exercising) people who represent the typical labour force potential experience more significant age-related performance drops, it might be in the interest of companies, perhaps, to systematically promote physical exercise for their employees.

\section{Literature}

BOOT, H. M. (1995). "How skilled were Lancashire cotton factory workers in 1833?", Economic History Review, 2, 283-303.

CRÉPON, B., DENIAU, N. \& PEREZ-DUARTE, S. (2003). Productivité et salaire des travailleurs ages. Revue francaise d'économie, 18, 157-185. ,

DEARY, I. J., WHALLEY, L. J., LEMMON, H., CRAWFORD, J. R. \& STARR, J. M. (2000). The stability of individual differences in mental ability from childhood to old age. Follow-up of the 1932 Scottish Mental Survey. Intelligence, 28, 49-55.

ERICSSON, K. A. \& LEHMANN A. C. 1996. "Expert and exceptional performance: Evidence of maximal adaption to task constraints. Annual Review of Psychology, 47, 273-305.

FAIR, R. C. (1994). How fast do old men slow down? The Review of Economics and Statistics, 76, 103-118.

FAIR, R. C. (2007). Estimated Age Effects in Athletic Events and Chess. Experimental Aging Research, 33, 37-57.

FAIR, R. C. (2008). Estimated Age Effects in Baseball. Journal of Quantitative Analysis in Sports (4), DOI: 10.2202/1559-0410.1074

H/EGELAND, T. \& KLETTE, T. J. 1999. "Do higher wages reflect higher productivity? Education, gender and experience premiums in a matched plant-worker data set.", in HALTIWANGER, J. L., SPLETZER,J. R., THEEUWES. J. \& TROSKE, K. 1999. The creation and analysis of employer-employee matched data, Elsevier Science, Holland.

HALTIVANGER, J. C., LANE, J. I. \& SPLETZER, J. R. (1999). Productivity differences across employers. The roles of employer size, age and human capital. American Economic Review, Papers and Proceedings, 89. 94-98.

HARRIS, M. \& HOLSTROM, B. (1982), A Theory of Wage Dynamics, Review of Economic Studies, 49, 316-33. 
HUTCHENS, R. (1989). Seniority,Wages and Productivity: A Turbulent Decade, Journal of Economic Perspectives, 3, 49-64.

ILMAKUNNAS, P., MALIRANTA, M. \& VAINIOMÄKI, J. (2004). The role of employer and employee characteristics for plant productivity. Journal of Productivity Analysis, 21, 249276

JOHNSON, P. (2003). Age, gender and the wage in Britain, in Scholliers, P. \& Schwarz, L. (Eds.),Worlds of wages, New York: Berghahn, pp. 229-49.

KOTLIKOFF, L. \& WISE, D. A. (1989). Employee Retirement and a Firm's Pension Plan. In D.A. Wise (Ed.): The Economics of Aging (pp. 279-334). Chicago: University of Chicago Press.

LAZEAR, E. P., MOORE, R. L. (1984). Incentives, productivity, and labor contracts, The Quarterly Journal of Economics, 99, 275-296.

MAITLAND, S. B., INTRIERI, R. C., SCHAIE, K. W. \& WILLIS, S. L. (2000). Gender differences and changes in cognitive abilities across the adult life span. Aging, Neuropsychology, and Cognition, 7, 32-53.

MC MORROW, V., ROEGER, W. (2004). The economic and financial market consequences of global ageing. Berlin.

NISHIMURA, K. G., MINETAKI, K., SHIRAI, M. \& KUROKAWA, F. (2002). Effects of information technology and aging work force on labor demand and technological progress in japanese industries: 1980-1998" Discussion Paper CIRJE-F-145, Faculty of Economics, University of Tokyo

OSTER, S. M. \& HAMERMESH, D. S. (1998), Aging and Productivity Among Economists, The Review of Economics and Statistics, 80, 154-156.

PARK, D. C., NISBETT, R. E. \& HEDDEN, T. (1999). Culture, cognition, and aging. Journal of Gerontology, 54 B, 75-84.

ROYSTON, P. \& ALTMAN, D. G. (1994). Regression using fractional polynomials of continuous covariates: parsimonious parametric modeling. Applied Statistics, 43, 429467.

ROYSTON, P. \& SAUERBREI, W. (2008). Multivariable model - building: A pragmatic approach to regression analysis based on fractional polynomials for modelling continuous variables. Hoboken, NJ: John Wiley.

RUSHALL, B. S. (2000). Some psychological factors for promoting exceptional athletic performance, Eye on Psi Chi, 4, 14-18.

SALTHOUSE, T. \& MAURER, T. J. (1996). Aging, job performance and career development. in J. E Birren \& K.W. Schaie eds., Handbook of the Psychology of Aging, 4th ed., Academic Press Inc.

SKIRBEKK, V. (2004). Age and individual productivity: A literature survey. In G. Feichtinger (Ed.), Vienna yearbook of population research, Vienna: Austrian Academy of Sciences Press: 133-153. http://www.iiasa.ac.at/ skirbekk/Demo2004EN.pdf

STEPHAN, P. E. \& LEVIN, S. G. (1988) Measures of scientific output and the ageproductivity relationship, in A. Van Raan, (Ed.), Handbook of Quantitative Studies of Science and Technology, 31-80.

UNITED NATIONS ORGANISATION (UNO) (2003), World population prospects: The 2002 Revision, New York. 
VERHAEGEN, P. \& SALTHOUSE, T. A. (1997), Meta-analyses of age-cognition relations in adulthood. Estimates of linear and nonlinear age effects and structural models. Psychological Bulletin, 122, 231-249.

WADA (2009). Report of the independent observers, XXIX Olympic Games, Beijing 2008. www.wada-ama.org/rtecontent/document/WADA_IO-Report_Bejing_2008_FINALFeb2009.pdf from April, 6th, 2009

WARR, P. (1994). Age and employment", in H. Triandis, M. Dunnette and L. Hough eds.. Handbook of Industrial and Organizational Psychology, 2nd Ed, 485-550, CA. Consulting Psychologist Press. 
